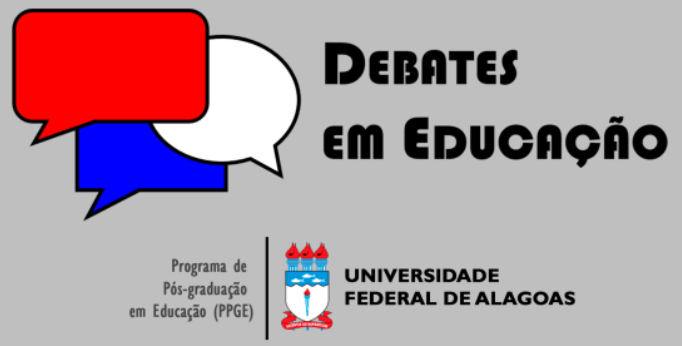

ISSN Eletrônico 2175-6600

Vol. 12 | Número Especial | 2020

Nayanne Nayara Torres da Silva

(9) iD

Universidade de Pernambuco (UPE)

nayannetorres@yahoo.com.br

Eliana Borges Correia de Albuquerque

9 iD

Universidade Federal de Pernambuco (UFPE) eliana.balbuquerque@gmail.com

\section{A HETEROGENEIDADE DE CONHECIMENTOS SOBRE O SISTEMA DE ESCRITA ALFABÉTICA: PRÁTICAS DE ENSINO E APRENDIZAGENS DOS ALUNOS}

\begin{abstract}
RESUMO
A presente investigação analisou a relação entre as práticas de alfabetização, no que se refere ao tratamento da heterogeneidade de conhecimentos sobre o sistema de escrita alfabética (SEA), e a progressão das aprendizagens de alunos do $2^{\circ}$ ano de uma escola da rede municipal de ensino da cidade de Recife - PE. Adotou-se, no estudo, uma abordagem qualitativa de pesquisa. Os dados da investigação, tratados com base na análise temática de conteúdo e obtidos por meio de observações em sala de aula e aplicação de atividades diagnósticas, evidenciaram uma atenção da professora à heterogeneidade de conhecimentos dos aprendizes e uma progressão das aprendizagens sobre o sistema de escrita alfabética da maioria dos alunos ao longo do ano letivo.
\end{abstract}

Palavras-chave: Alfabetização. Heterogeneidade. Aprendizagens.

\section{THE HETEROGENEITY OF KNOWLEDGE ABOUT THE ALPHABETICAL WRITING SYSTEM: STUDENT TEACHING AND LEARNING PRACTICES}

\begin{abstract}
The present invetigation analyzed the relationship between literacy practices, with regard to the heterogeneity treatment of knowledge in the alphabetical writing system (SEA), and the learning progression of 2 nd year students at a public school located in the city of Recife-PE education system. A qualitative research approach was adopted. The research data, treated through the thematic content analysis and obtained through classroom observations and application of diagnostic activities, shoed the teacher's attention to the heterogeneity of knowledge of the learners and a progression about the alphabetic writing system of the majority of students throughout the school year.
\end{abstract}

Keywords: Literacy. Heterogeneity. Learning.

Submetido em: 14/04/2020

Aceito em: 09/07/2020

Publicado em: 10/12/2020

dol http://dx.doi.org/I0.28998/2 I75-6600.2020v I 2nEspp79-99 


\section{INTRODUÇÃO}

$\bigcirc$ atendimento à heterogeneidade de conhecimentos dos aprendizes em sala de aula tem gradativamente ganhado espaço no âmbito das discussões sobre alfabetização. Embora a preocupação em instituir métodos ou metodologias de alfabetização não seja uma preocupação recente, percebemos, nos últimos anos, uma atenção maior para com as aprendizagens dos alunos. Temos observado o crescente interesse de investigações sobre alfabetização que atentam para o fenômeno da heterogeneidade de conhecimentos (OLIVEIRA, 2004/20I0; CRUZ 20I2; SILVEIRA, 20I3; SILVA, 20I4; SA, 20I 5; SILVA, 2016; DOURADO, 2017; NASCIMENTO, 2017; dentre outras), o que parece se relacionar a um movimento de protagonismo dos aprendizes no processo de alfabetização.

Tal movimento teve início na década de 1980, com a difusão dos estudos sobre a Psicogênese da Escrita, desenvolvida por Emília Ferreiro e Ana Teberosky. Desde essa época, o campo da alfabetização vem propondo novos encaminhamentos que buscam romper com a visão associacionista/empirista de ensino, na qual o educando é colocado na posição de mero receptor de um código, como fazem os métodos tradicionais de alfabetização. Nesse caminho, em que se busca ultrapassar essa visão, vem-se abrindo espaço para uma perspectiva que considera o aprendiz como sujeito ativo desse processo, ao mesmo tempo em que defende a necessidade de um ensino sistemático das propriedades e convenções do Sistema de Escrita Alfabética (doravante SEA), como também dos usos e funções sociais da leitura e da escrita.

Nessa configuração, as dificuldades de aprendizagem precisam ser consideradas na ação docente, por meio de práticas que reconheçam e atendam aos diferentes conhecimentos dos aprendizes sobre a escrita no coletivo da sala de aula. São os conhecimentos oriundos de fora da escola e as experiências vivenciadas na Educação Infantil que refletirão, em um primeiro momento, a heterogeneidade do grupo classe. Isso poderá influenciar as práticas desenvolvidas pelos professores, uma vez que o atendimento aos diferentes conhecimentos dos alunos sobre o ler e escrever demandam ações diferenciadas que levem em consideração as singularidades dos discentes.

Considerando que, no espaço da sala de aula, os saberes e as práticas dos professores alfabetizadores são (re)inventados cotidianamente na tentativa de desenvolver uma pedagogia diferenciada, que, conforme observa Chartier (2007), impõe-se com mais evidência na classe de alfabetização, desenvolvemos uma pesquisa que visou investigar como os alunos do $2^{\circ}$ ano do ciclo de alfabetização progrediram ao longo de um ano letivo em suas aprendizagens de escrita alfabética e que práticas mobilizadas pela professora da turma pareciam atender aos diferentes conhecimentos de escrita desses aprendizes. 
Diante disso, tivemos o objetivo de analisar a relação entre as práticas de alfabetização, no que se refere ao tratamento da heterogeneidade de conhecimentos sobre o SEA, e a progressão das aprendizagens dos alunos. Para isso, buscamos analisar a heterogeneidade de conhecimentos dos alunos sobre a escrita, os encaminhamentos e intervenções realizados pela professora no desenvolvimento das atividades relacionadas à apropriação e consolidação da escrita alfabética e os avanços da turma no decorrer do ano letivo.

Nessa direção, apresentaremos, inicialmente, algumas reflexões teóricas sobre diferentes perspectivas de alfabetização e suas implicações no tratamento da heterogeneidade, assim como sobre os saberes e as ações docentes no cotidiano da sala de aula. Em seguida, após situarmos os aspectos metodológicos da pesquisa, discutiremos os resultados encontrados e teceremos algumas considerações finais.

\section{REVISÃO BIBLIOGRÁFICA}

\section{I Pensando a heterogeneidade de conhecimentos dos aprendizes sob diferentes perspectivas de alfabetização}

Atualmente, as escolas desenvolvem, de modo geral, um tipo de alfabetização coletiva que é fruto de uma construção histórica. No Brasil, no período Colonial e até mesmo no Império, quando a educação ainda não era um direito de todos e não havia a obrigatoriedade de frequência à escola, observava-se intensa presença do ensino individual (FILHO; VIDAL, 2000), muitas vezes realizado em casa ou em espaços inadequados de sala de aula. Nesse modo de ensino, o preceptor ou professor ensinava cada aluno individualmente, mesmo quando sua classe era constituída por vários alunos.

Devido, principalmente, à necessidade de generalizar a instrução para um grande número de indivíduos, o que resultou no processo de escolarização de massa (FILHO; VIDAL, 2000; CHARTIER, 20 I 5), o ensino individual deu lugar a uma pedagogia coletiva. No Brasil, na época da República, instalamse as escolas seriadas e difunde-se o método simultâneo, no qual, "de acordo com sua faixa etária e seu nível de conhecimento, os alunos passariam a se organizar em turmas classificadas em séries e o professor ou professora passaria a desenvolver atividades coletivas com eles, utilizando um mesmo material didático." (BATISTA; et al., 2002, p. 27).

Foi nesse modelo de organização de ensino que os métodos de alfabetização de base sintética (alfabético, silábico ou fônico) e analítica (palavração, sentenciação, global) foram desenvolvidos com o objetivo de ensinar a ler e escrever cada vez mais rápido um número maior de crianças. Embora tivessem pontos de partida diferentes (enquanto os sintéticos iniciavam o trabalho por meio das unidades menores 
da língua, os analíticos partiam das unidades linguísticas maiores), tais métodos não se diferenciavam quanto à maneira de conceber a alfabetização, que era vista como a aquisição de um código de transcrição da fala, que seria aprendido por meio da repetição e memorização.

No quadro de tais métodos, não se considerava, via de regra, a necessidade de propor aos alunos atividades diferenciadas que considerassem os diferentes conhecimentos e percursos dos aprendizes, uma vez que as atividades padronizadas e coletivas seriam suficientes para garantir que todas as crianças de uma turma, considerada como homogênea, memorizassem letras, sílabas e/ou palavras.

Se essa perspectiva tradicional de alfabetização não estava preocupada com a heterogeneidade de conhecimentos dos aprendizes, a teoria psicogenética da escrita (FERREIRO; TEBEROSKY, 1999), difundida no cenário brasileiro na década de 1980, inaugurou, de certo modo, uma atenção a esse fenômeno, ao considerar o aprendiz em sua singularidade. Tal abordagem instaurou uma verdadeira revolução conceitual no campo da alfabetização, deslocando a atenção, conforme esclarece Ferreiro (200I), do "como se ensina" para o "como se aprende".

No contexto brasileiro, na mesma época da difusão da teoria da Psicogênese da Escrita, vimos surgir, em vários estados (São Paulo, Minas Gerais, Pernambuco), a proposta de implantação dos ciclos básicos de alfabetização. Trata-se de uma proposta que surgiu com o intuito de "[...] regularizar o fluxo de alunos ao longo da escolarização, a fim de assegurar que todos possam cumprir os anos de estudo previstos para o ensino obrigatório, sem interrupções e retenções que inviabilizem a aprendizagem efetiva e uma educação de qualidade" (BARRETTO; SOUSA, 2004, p. 33).

Nessa proposta, visava-se contribuir para o sucesso dos aprendizes na escola e, para isso, ampliouse o tempo de aprendizagem dos alunos. Entretanto, essa perspectiva de correção do fluxo, existente no ideário de ciclo, não é, porém, garantia de uma pedagogia diferenciada, podendo servir como um mero "descongestionamento" do sistema. Em outras palavras, embora a proposta de ciclos considere a heterogeneidade de conhecimentos, ela não assegura, necessariamente, o atendimento desse fenômeno por meio de práticas de ensino ajustadas às necessidades dos aprendizes.

O estudo de Oliveira (20।0), ao analisar a existência (ou não) de uma progressão das atividades de língua portuguesa no interior do ciclo de alfabetização, tomando como base as práticas docentes realizadas em sala, enfatizou a necessidade de se priorizar $\mathrm{o}$ atendimento dos diferentes ritmos de aprendizagem e o avanço do educando no interior do ciclo, evidenciando que o tipo de organização escolar adotado não é garantia de atendimento à heterogeneidade de conhecimentos dos alunos.

Em síntese, podemos salientar que uma teoria psicológica sobre os processos de construção de conhecimentos sobre a escrita (a "Psicogênese da escrita") e uma forma diferente de organização escolar (os ciclos de aprendizagem), pareceram impulsionar uma nova maneira de considerar os diferentes percursos e conhecimentos dos aprendizes e os modos de tratá-los no contexto da sala de aula. Contudo, 
a materialização de um atendimento à heterogeneidade de conhecimentos dos aprendizes relaciona-se a outros aspectos para além dessas teorias e decretos, dentre eles os saberes e práticas que os docentes mobilizam em suas ações cotidianas.

\subsection{As maneiras de fazer dos professores no contexto da sala de aula}

Nas práticas desenvolvidas, no espaço da sala de aula, os professores mobilizam diferentes saberes construídos ao longo do tempo e de sua carreira profissional. Tais saberes, revelados nas ações docentes, são cotidianamente movimentados na relação que o educador institui com seus pares, com as prescrições oficiais, com seus alunos, dentre outros atores.

Em meio aos múltiplos saberes constitutivos da ação docente, os oriundos da experiência são os que mais se sobressaem. Segundo Tardif (2008), os saberes experienciais são adquiridos por meio das práticas cotidianas, e não se encontram, portanto, definidos nem nos currículos, nem nas instituições de formação, muito menos sistematizados como teoria e doutrina. É no exercício diário de sua função, em meio às ações impostas pelos condicionantes do contexto escolar, que esse saber experiencial vai-se constituindo.

São esses saberes experienciais que propiciam a construção dos esquemas profissionais, que, segundo Goigoux (2007), referem-se às formas organizadas e estabilizadas de ensino que os professores acionam no processo de mediação entre as crianças e os conhecimentos, com vistas a operacionalizar um ensino ajustado às potencialidades delas. Trata-se, portanto, de procedimentos regulares que vão sendo estabilizados ao longo do tempo nas ações docentes. Essas ações são construídas por acomodações em meio a diferentes variações contextuais que permitem, segundo Maurice (2006), a flexibilização e a economia cognitiva diante de situações e ambientes dinâmicos e complexos, como é o ambiente da sala de aula.

Quanto mais experiente for o docente, mais esquemas de ação ele terá "armazenado". Tais esquemas, que nem sempre são mobilizados de forma planejada e intencional, precisam, conforme sinalizam Goigoux e Vergnaud (2005), ser analisados nas condutas dos professores em situações de sala de aula, pois dizem respeito aos registros de atividade que acontecem em interação com os alunos. Além disso, os autores também sinalizam a função assimiladora dos esquemas profissionais. Isso significa que, para enfrentar uma nova situação ou dificuldade em sala de aula, o docente acionará esquemas antigos, que foram utilizados em situações ocorridas anteriormente, porém semelhantes à situação atual e, diante disso, conseguirá elaborar uma conduta profissional adaptada.

Atrelado a isso, a prática docente também pode agregar uma multi-agenda de gestos profissionais que constituem esses esquemas profissionais. Segundo Bucheton e Soulé (2009), os gestos profissionais 
correspondem à ação do professor situada na diversidade de situações da sala de aula (o tempo, as interações, os saberes, as tarefas, a relação com o conhecimento, as atitudes dos alunos, entre outros aspectos) e à atualização de suas preocupações, podendo se referir tanto à palavra quanto aos movimentos corporais.

Trata-se de cinco as preocupações centrais que regem a prática docente em sala e que foram definidas a partir de um modelo de multi-agenda, elaborado pela Equipe de Pesquisa Tecnológica em Educação (ERTE 40) da cidade de Montpellier, na França. Nesse modelo, consagraram-se cinco gestos profissionais que definem as inquietações da atividade do professor, quais sejam: I) gerenciamento da atividade, 2) atmosfera da classe, 3) tecelagem, 4) apoio e 5) o objeto de conhecimento. (BUCHETON; SOULÉ, 2009).

As preocupações que partem dessa multi-agenda estão ancoradas, segundo Bucheton e Soulé (2009, p. 32, tradução nossa), nas ações de: "I) gerenciar e organizar o progresso da lição; 2) manter um espaço de trabalho e de colaboração linguística e cognitiva; 3) explicitar o significado do que está acontecendo; 4) apoiar o trabalho em andamento e 5) tudo isso com foco na aprendizagem de qualquer natureza". Tais preocupações se mostram como pilares que dão suporte ao ato ordinário na sala de aula, assim como, para os conhecimentos, as experiências e habilidades do profissional docente.

Dentro desse quadro de multi-agenda dos gestos profissionais, têm-se ainda as posturas assumidas pelos docentes no desenvolvimento de suas atividades, que funcionam como

[...] um esquema pré-construído de ações intelectuais e linguísticas que o sujeito evoca em resposta a uma situação ou tarefa escolar dada. A postura é relativa à tarefa, mas é construída na história social, pessoal e escolar do sujeito. Os sujeitos dispõem de uma ou várias posturas para negociar a tarefa. Eles podem mudar de postura durante a tarefa de acordo com o novo significado que eles Ihes atribuem (BUCHETON, 2006, p. 32, tradução nossa).

Bucheton e Soulé (2009), considerando a diversidade de comportamentos e ajudas ofertadas pelos docentes a seus alunos, sinalizaram para a existência de seis posturas: de controle, de acompanhamento, de deixar fazer, de sobreapoio ou contra-apoio, de ensino e, por fim, uma postura chamada de "mágica". A "postura de controle" desenvolvida pelo professor visa a um enquadramento da situação, conduzindo de maneira rígida o progresso das tarefas e procurando fazer com que todo o grupo avance em sincronia. Já na "postura de acompanhamento", há uma ajuda pontual, que pode ser individual ou coletiva, desenvolvida de maneira lateral em função do progresso da tarefa e dos obstáculos a serem superados.

Por outro lado, a "postura de deixar fazer" refere-se a um trato de confiança, na qual o educador atribui aos discentes toda a responsabilidade por seu trabalho, autorizando-os a experimentar os caminhos que escolhem. A "postura de sobreapoio ou contra-apoio", por sua vez, diz respeito à interferência do docente que, diante da necessidade de avançar mais rapidamente com a turma, pode acabar fazendo a tarefa no lugar do aluno. As interferências também acontecem na "postura de ensino", na qual o professor 
formula e estrutura os saberes e as normas, com vistas à demonstração para os alunos. Na "postura mágica", o docente capta a atenção das crianças, mesmo que de forma momentânea, por meio de jogos, gestos teatrais, narrativas marcantes, entre outros aspectos. (BUCHETON; SOULÉ, 2009).

Diante disso, sinalizamos que é na ação desenvolvida em sala de aula que o professor se torna professor, por meio das práticas que realiza, das situações didáticas e pedagógicas que experimenta/(re)traduz/(re)organiza, e pelos procedimentos que utiliza. As práticas docentes englobariam, então, os saberes mais amplos de cada sujeito, elaborados ao longo de sua história de vida e profissional, como também os esquemas, posturas e gestos profissionais que se consolidam por meio das fabricações de suas práticas.

\section{ABORDAGEM METODOLÓGICA DA PESQUISA}

Para atender ao objetivo do estudo, pautamo-nos em uma abordagem qualitativa e quantitativa, uma vez que não há dicotomia entre quantidade e qualidade, podendo, ambas, se complementar, conforme esclarece André ( 1995).

Para participar da pesquisa, selecionamos uma professora do $2^{\circ}$ ano do Ensino Fundamental considerada, na rede municipal de ensino na qual trabalhava, como boa alfabetizadora - que atuava em uma escola pública da cidade de Recife-PE e os alunos matriculados na referida turma. Além disso, escolhemos a turma do $2^{\circ}$ ano pelo fato de acreditarmos que no ciclo de alfabetização', constituído pelos três primeiros anos do Ensino Fundamental, esse é o ano em que a heterogeneidade se apresenta de forma mais latente.

Com o objetivo de manter o anonimato dos participantes da pesquisa, a docente será tratada, neste artigo, por "Professora M" e os alunos da turma por AI, A2, A3 e assim respectivamente, sendo o número estabelecido de acordo com a ordem alfabética da classe. No que se refere ao perfil da professora investigada, destacamos que, em relação à experiência profissional, a Professora Mé uma docente iniciante, possuindo apenas três anos de experiência na docência, todos dedicados ao ciclo de alfabetização. Além disso, possui duas graduações, uma em Letras e outra em Pedagogia, ambas realizadas em instituiç̧ões públicas (Universidade Estadual e Federal de Pernambuco, respectivamente), e mestrado em educação pela Universidade Federal de Pernambuco.

Em relação aos procedimentos metodológicos, realizamos observações das práticas de ensino da professora e atividades diagnósticas de escrita de palavras com os alunos da turma. Foram observados I5

\footnotetext{
' Em 20 16, ano em que a coleta de dados da presente pesquisa foi realizada, o ciclo de alfabetização integrava os três primeiros anos do Ensino Fundamental, algo que foi alterado com a promulgação da Base Nacional Comum Curricular (BNCC), em 20 17, e com a Política Nacional de Alfabetização (PNA), em 20 I9, que passaram a destinar apenas os dois primeiros anos para a consolidação da alfabetização.
} 
(quinze) dias de aulas, sendo dois grupos de 5 (cinco) dias consecutivos, com um intervalo de duas semanas entre eles, no primeiro semestre letivo, e um grupo de 5 (cinco) dias consecutivos, no segundo semestre do referido ano letivo. Tal dinâmica de observação justifica-se porque intencionávamos observar, de segunda a sexta-feira, como a Professora M organizava as atividades, distribuía os alunos em sala de aula, etc.

As atividades diagnósticas correspondentes à escrita de palavras com apoio de imagens foram aplicadas no início (mês de abril, antes de iniciarmos as observações) e no final do ano letivo (mês de outubro, depois de termos finalizado as observações). Tais atividades foram realizadas com vistas a identificarmos o perfil de entrada e de saída dos aprendizes no que se refere à apropriação da escrita alfabética e da norma ortográfica.

As atividades realizadas nos dois momentos continham as mesmas palavras, contemplando diversas construções silábicas (consoante-vogal, vogal-consoante; consoante-vogal-consoante, consoanteconsoante-vogal, dentre outras). Entretanto, as gravuras e a ordem de apresentação de ambas as atividades foram diferentes. A partir disso, analisamos as escritas dos aprendizes com base nas discussões teóricas de Ferreiro e Teberosky (1999), Ferreiro (200 I) e Morais (20 I 2), assim como nas categorias elaboradas por Cruz (2012), e definimos os seguintes níveis:

Pré-Silábico inicial (PI): nessa fase, as crianças podem fazer uso de rabiscos por ainda não reconhecerem as letras convencionais que devem ser utilizadas na escrita. Além disso, também podem usar apenas uma letra para escrever as palavras ou usar apenas as letras de seu nome, repetir algumas letras várias vezes nas palavras diferentes, usar uma grande variedade de letras ou grafar palavras de memória. Nesse estágio, as escritas não têm relação com as partes sonoras das palavras.

Pré-Silábico com início de fonetização (PII): é o momento em que as crianças começam a estabelecer em suas escritas algumas correspondências grafema/fonema nas sílabas ou letras iniciais e/ou finais das palavras, enquanto que no decorrer da palavra não estabelecem essas relações.

Silábico (S): a criança registra uma letra para cada sílaba da palavra. Esse registro pode acontecer com base numa correspondência sonora da letra com a sílaba representada, havendo preocupação com a ordem das letras e suas respectivas sílabas (Silábico qualitativo), ou utilizando letras sem relação com a sílaba oral (Silábico quantitativo).

Silábico-Alfabético (SA): as crianças começam a refletir no nível do fonema e com isso passam a ficar insatisfeitas com a quantidade de letras que estavam utilizando, percebendo a necessidade de grafar mais de uma letra para representar uma sílaba. No entanto, ainda não têm consistência para marcar todos os fonemas, usando ora uma única letra, ora mais de uma, e em muitas ocasiões não usam o grafema adequado. 
Alfabético inicial (Al): as crianças têm pouco domínio das correspondências letra/som, embora já tenham compreendido a base alfabética do nosso sistema de escrita (uma letra para cada fonema). Sendo assim, escrevem sem predomínio do valor sonoro convencional, usando, na maioria das vezes, grafemas não pertinentes para representar os fonemas.

Alfabético intermediário (All): apresentam um razoável domínio das correspondências letra/som, utilizando, predominantemente, grafemas com valor sonoro convencional. No entanto, por desconhecimento, usam, às vezes, letras que não correspondem ao fonema em questão, podendo, também, omitir sílabas complexas.

Alfabético consolidado (AllI): as crianças apresentam pouca dificuldade nas correspondências letra/som, tendo em vista que já dominam a estrutura do sistema, assim como o valor sonoro convencional da maioria dos grafemas da língua. Contudo, ainda cometem alguns erros ortográficos.

Alfabético com escrita convencional (AIV): É a fase em que as crianças escrevem todas as palavras corretamente, respeitando todas as correspondências som/grafia e sem cometer nenhum erro ortográfico, podendo não utilizar corretamente a acentuação.

tratamento dos dados, provenientes dessas atividades e das observações realizadas, foi desenvolvido por meio da análise de conteúdo do tipo temática categorial, envolvendo as etapas sugeridas por Bardin (2004): pré-análise, análise do material (codificação e categorização da informação) e tratamento dos resultados, inferência e interpretação. Inicialmente, realizamos uma "leitura flutuante" do material obtido por meio das observações. A partir dessa leitura dos dados, surgiram os temas que foram listados e submetidos aos processos de codificação e categorização, em que as informações foram condensadas e destacadas, conforme sugere Bardin (2004). Com as categorias de análise construídas, partimos para a inferência e a interpretação dos dados.

\section{ANALISANDO A PROGRESSÃO DAS APRENDIZAGENS DOS ALUNOS E AS PRÁTICAS DE ENSINO FACE À HETEROGENEIDADE DE CONHECIMENTOS SOBRE A ESCRITA ALFABÉTICA}

tratamento da heterogeneidade de conhecimentos dos aprendizes sobre a escrita na sala de aula foi analisado a partir das ações que a Professora $M$ desenvolvia ante esse fenômeno. Além disso, a progressão das aprendizagens dos alunos, que também acontecia, dentre outros aspectos, em decorrência das ações realizadas pela docente em sala, foi analisada com base nas diagnoses aplicadas no início e no final do ano letivo, conforme dissemos anteriormente.

Para discutirmos sobre as ações docentes, com vistas a contemplar o atendimento à heterogeneidade de conhecimentos sobre a escrita dos alunos, consideramos importante, inicialmente, 
sinalizarmos o quão heterogêneo era o grupo classe da professora. Diante disso, apresentamos, no Quadro I, os níveis de apropriação da escrita alfabética em que se encontravam cada um dos aprendizes.

Quadro I - Perfil inicial de escrita dos alunos da turma do $2^{\circ}$ ano da professora $M$.

\begin{tabular}{|c|c|c|c|}
\hline Níveis de apropriação do SEA - Perfil Inicial & Identificação dos Alunos & \multicolumn{2}{|c|}{ Qtd. } \\
\hline Pré - Silábico (PI) & $\mathrm{A}|0, \mathrm{~A}| 9$ & 2 & $8,3 \%$ \\
\hline Pré - Silábico com início de fonetização (PII) & $\mathrm{A} 5, \mathrm{~A}|3, \mathrm{Al} 6, \mathrm{~A}| 7, \mathrm{Al} 8, \mathrm{~A} 20$ & 6 & $25 \%$ \\
\hline Silábico (S) & $\mathrm{A} 8, \mathrm{~A} \mid 4$ & 2 & $8,3 \%$ \\
\hline Silábico - Alfabético (SA) & $\mathrm{A} 7, \mathrm{~A} \mid \mathrm{I}, \mathrm{A} 24$ & 3 & $12,5 \%$ \\
\hline Alfabético inicial (Al) & - & 0 & $0 \%$ \\
\hline Alfabético intermediário (All) & $\mathrm{A} 3, \mathrm{~A} 4, \mathrm{~A} 6, \mathrm{~A} 9, \mathrm{~A} 2 \mathrm{I}$ & 5 & $20,8 \%$ \\
\hline Alfabético consolidado (AllI) & $\mathrm{Al}, \mathrm{A} 2, \mathrm{AI} 2, \mathrm{AI} 5, \mathrm{~A} 22, \mathrm{~A} 23$ & 6 & $25 \%$ \\
\hline Alfabético com escrita convencional (AIV) & - & 0 & $0 \%$ \\
\hline Total & - & 24 & $\approx 100 \%$ \\
\hline
\end{tabular}

Fonte: Dados da pesquisa (20|6).

É possível identificarmos a existência de todas as hipóteses de escrita, exceto da alfabética inicial e da escrita convencional, em um mesmo grupo-classe, havendo, no entanto, uma equivalência entre alunos da hipótese pré-silábica com início de fonetização (25\%) com a alfabética consolidada (25\%). Apesar de ser alta a incidência de crianças nos níveis iniciais de apropriação do SEA (4I,6\% de alunos com hipóteses pré-silábicas e silábicas), percebemos um quantitativo considerável de alunos $(45,8 \%)$ que já pensavam o sistema com base em uma hipótese alfabética de escrita.

No início do ano letivo, quase metade dos alunos (45,8\%), já apresentavam escritas alfabéticas, além disso, 12,5\% se encontravam na fase transitória e de grande aprendizado das correspondências somgrafia (silábico-alfabética), já evidenciando um pensamento ao nível do fonema. Sendo assim, a turma se apresentava bastante heterogênea, haja vista o grupo de alunos que ainda representava suas notações com base em hipóteses pré-silábicas e silábicas de escrita e outro grupo que já pensava alfabeticamente, ou que iniciava esse processo (no caso dos silábico-alfabéticos), mas que divergia quanto ao domínio das correspondências entre letra e som.

Para dar conta dessa heterogeneidade, a Professora M mobilizava "esquemas profissionais" (GOIGOUX, 2007), como: o atendimento individualizado; a ajuda/intervenção; os agrupamentos; a interação professora-aluno nos momentos coletivos de ensino; as atividades diferenciadas; e o caderno de reforço. Em algumas dessas situações, também agregava "gestos profissionais" e "posturas" (BUCHETON; SOULÉ, 2009) para contemplar tanto os alunos que apresentavam dificuldades de aprendizagem, quanto os que já se encontravam em níveis mais avançados de leitura e escrita.

No que diz respeito ao atendimento individualizado, realizado em cinco das quinze aulas observadas (5/I5), percebemos que a professora dispensava uma atenção individual a alguns alunos, em especial àqueles que apresentavam mais dificuldades de aprendizagem em relação à leitura e à escrita. 
Além de dispensar essa atenção direta, a professora mantinha esses alunos em lugares estratégicos da sala de aula - próximo ao seu birô e nas bancas da frente -, com vistas a acompanhá-los diariamente nas atividades.

Esse esquema era mobilizado basicamente com os mesmos aprendizes (A5, A6, A8, Al3, Al4, A I6, AI7, A I 8, A24), que apresentavam dificuldades na apropriação do SEA, sendo que ora o atendimento acontecia ao final da aula, ora no decorrer da atividade coletiva. $\bigcirc$ atendimento individualizado realizado ao final da aula revelava uma forma de diferenciação do ensino que se aproxima de alguns resultados evidenciados na investigação coordenada por Goigoux (2016), com cento e trinta e cinco professores de turmas do Curso Preparatório (CP) e do Curso Elementar I (CE I), que correspondem aos dois primeiros anos do Ensino Fundamental aqui no Brasil. Nesse estudo, os docentes foram investigados com vistas a identificar as características das práticas que se revelavam mais eficazes e equitativas para a qualidade da aprendizagem dos alunos. Dentre os resultados, o autor destacou a ajuda que os professores forneciam fora da sala de aula a 26\% dos aprendizes que apresentavam dificuldades, aproveitando desses momentos para realizar atividades pedagógicas complementares.

Embora a Professora M não realizasse esse atendimento fora da sala de aula, o atendimento "extra" realizado aconteceu em momentos posteriores à aula. Ou seja, o trabalho com a classe já havia terminado, sendo a maioria dos alunos dispensados enquanto ela desenvolvia atividades complementares que enfocavam a apropriação do sistema de notação alfabética, assim como a leitura, com um grupo que necessitava dessa ajuda. Nessas situações, as crianças eram levadas a compreender, dizer e fazer a tarefa proposta, evidenciando-se o gesto profissional de apoio (BUCHETON; SOULÉ, 2009).

atendimento individual no decorrer da atividade coletiva acontecia no birô da professora com as crianças que também apresentavam dificuldades na leitura e na escrita. A docente atendia esses aprendizes na atividade que poderia ser a mesma realizada pelo grupo-classe ou em uma tarefa diferente. Nessas situações em que as atividades eram a mesma para o coletivo da sala, a professora $M$ ainda realizava ajudas e intervenções diretas com aqueles que apresentavam dificuldades para respondê-las. Isso aconteceu em sete aulas (7//5), variando-se a quantidade e os alunos que foram ajudados, enquanto o foco da ajuda sempre girava em torno do sistema de notação alfabética e da leitura.

Nessas situações, havia a mobilização do gesto de apoio, já evidenciado no trabalho extraclasse, assim como a postura de acompanhamento (BUCHETON; SOULÉ, 2009), em que a docente conduzia esses momentos. Assim, a professora dispensava uma ajuda a esses aprendizes de maneira lateral, ao passo que também se mantinha atenta ao coletivo da sala, em função do avanço da tarefa e dos obstáculos a serem superados. Tratava-se, portanto, de uma ação que se concentrava na figura docente.

Contudo, também existia, por parte da Professora $M$, tentativas de instituir momentos em que os alunos mais "experientes" da sala - aqueles que apresentavam bom domínio do SEA -, pudessem ajudar 
ou supervisionar as atividades dos alunos em níveis mais iniciais de escrita. Isso era realizado por meio dos agrupamentos, nos quais as crianças eram estimuladas a situações de cooperação e ajuda entre si.

É importante destacar que a sala de aula já apresentava uma organização na qual as bancas eram dispostas em pares e que alguns discentes tinham lugares determinados pela docente. Tal organização era feita com vistas a possibilitar a ajuda mútua entre alguns aprendizes, de facilitar a supervisão daqueles que apresentavam dificuldades de aprendizagem e de manter a ordem em sala, deixando algumas crianças sentadas sozinhas, sem dupla. No entanto, houve situações em que as duplas ou grupos foram estimulados a trabalharem em conjunto, acontecendo em oito das quinze aulas observadas (8//5).

Sendo assim, a professora M cooperava com a atmosfera da sala, uma vez que pretendia com os agrupamentos organizar "o encontro intelectual, relacional, afetivo e social entre indivíduos confrontados com uma situação que contém questões a serem gerenciadas em comum" (BUCHETON; SOULÉ, 2009, p. 34, tradução nossa). Com isso, intencionava construir uma atmosfera que captasse a atenção dos alunos e os tornassem integrantes ativos da classe, podendo compartilhar falas, pensamentos, aprendizagens, assim como a escuta do outro.

Nesses agrupamentos em duplas, a professora procurava agrupar as crianças que apresentavam diferentes níveis de conhecimento acerca do sistema de escrita alfabética, porém não tão distantes, haja vista a intenção em propiciar a cooperação nas atividades. Diante disso, " [...] a intervenção do professor aparece como essencial para a produtividade e a efetividade do trabalho cooperativo entre alunos e para a atualização de suas contribuições potenciais para a aprendizagem que estes realizam nas situações de sala de aula [...]" (COLOMINA; ONRUBIA, 2004, p. 292).

Nessa perspectiva, geralmente se sentavam juntos A2 e Al 8 (alfabético consolidado e pré-silábico com início de fonetização); A9 e A20 (alfabético intermediário e pré-silábico com início de fonetização); A8 e AI 5 (silábico e alfabético consolidado); AII e Al3 (silábico-alfabético e pré-silábico com início de fonetização); A7 e AI 9 (silábico-alfabético e pré-silábico); AI 4 e Al 6 (silábico e pré-silábico com início de fonetização); e sozinhas as crianças A4, A12, A22 e A23 (com hipóteses alfabéticas). Apesar das discrepâncias de hipóteses de algumas dessas duplas, a intencionalidade da professora parecia ser justamente essa, tendo em vista seu objetivo de um ajudar o outro.

Já com os aprendizes que se sentavam sozinhos, embora apresentassem uma hipótese alfabética de escrita, podendo ajudar outras crianças no desenvolvimento das atividades em sala, eles eram mantidos sem pares devido à conversa. No entanto, muitas vezes, eram colocados nos agrupamentos com a função de coordenar a atividade proposta. Com isso, a Professora M revelava, para o desenvolvimento de seu trabalho de alfabetização, saberes ligados a "Conhecimentos de tipo pedagógico" (CHARTIER, 2007). Segundo Morais (20|2, p. II5), "tais saberes são fundamentais, porque lhes permitem, na sala de aula, tomar boas decisões sobre como usar o tempo, sobre como organizar as crianças para fazer determinadas 
atividades (trabalho coletivo, em grupos, em duplas, individual), sobre como avaliar os desempenhos dos alunos etc". Ou seja, ações que facilitam a organização e o desenvolvimento dos trabalhos na classe.

Diante disso, a professora revelava um olhar atento à heterogeneidade da sua turma, procurando atender aos alunos com dificuldades na escrita e integrar nas tarefas as crianças com hipóteses mais avançadas. Isso ficou perceptível em uma das aulas observadas (Aula 03), quando a docente formou grupos para realizar uma brincadeira na qual as crianças precisavam pensar e escrever em uma folha de papel ofício palavras que rimavam com as que eram faladas por ela. Para isso, os alunos que já dominavam o SEA ficaram encarregados no grupo de escrever na folha a palavra que havia sido pensada coletivamente e os que ainda apresentavam dificuldades foram solicitados pela professora a escreverem a palavra, que havia sido pensada no grupo e escrita na folha pelo aluno que dominava o SEA, no quadro, sem o suporte da folha.

A intenção de chamá-los para o quadro era de estimular a reflexão acerca da escrita da palavra e, consequentemente, de identificar a dificuldade do aluno. Sendo assim, AI 4, AI7, AI 8, A20 e A24 (crianças de nível silábico, silábico-alfabético e pré-silábico com início de fonetização), ao serem chamadas ao quadro, foram beneficiadas pelo esquema profissional correspondente à interação professora-aluno realizada nos momentos coletivos de ensino. Nessas interações, ocorridas em duas aulas do conjunto de quinze observadas, a docente propiciava a reflexão acerca do SEA tanto para o aprendiz que era chamado para frente da sala, quanto para os demais, uma vez que essa ação era feita no coletivo.

Além disso, é válido mencionar que o momento de escrita na folha também era supervisionado pela Professora M, que passava entre os grupos para observar como os alunos estavam desenvolvendo a tarefa. $O$ extrato de aula abaixo sinaliza a maneira como a docente interagia com as crianças no momento em que elas eram solicitadas a escrever as palavras no quadro.

Professora M: Presta atenção agora! Eu vou colocar uma palavra aqui no quadro e vocês vão ter que aí no grupo procurar uma palavra que rime com a palavra que eu vou colocar aqui no quadro. Como assim, tia? Vamos dizer... "BARRIGA"! No grupo, vocês vão ter que pensar uma palavra que rima com "BARRIGA". [...] Então, no grupo, vocês vão pensar a palavra e vão escrever. Vai passar o papel na mão de todo mundo... aí Al 8 diz assim: "Ah! mas eu não sei escrever." Aí o colega vai ajudar você a escrever. Eu vou dar um tempo, aí quando disser "parou", vão ter que me dizer e escrever. Então, presta atenção como se escreve, presta atenção no som, porque se tiver errado não vai marcar ponto. (Após essas orientações a professora inicia a atividade falando as palavras que os alunos precisavam rimar. Ao ditar a palavra "GALINHA" e chamar alguns alunos até o quadro, a docente se depara com a dificuldade de um dos aprendizes).

Professora M: Qual foi a palavra que você pensou?

AI8: "GATINHA"

Professora M: Tente escrever aqui. "GA - TI - NHA" (O aluno escreve as duas primeiras sílabas da palavra e fica na dúvida quanto à escrita da sílaba final). Como é o "NHA"? (A docente repete a palavra "GATINHA" dando ênfase ao som final e repetindo-a várias vezes até que o aluno a escreva).

Professora M: Bora lá! Vamos ver! Tinha que terminar em "NHA". No grupo A está escrito o quê? (A professora repete todas as palavras escritas no quadro pelas crianças de cada grupo e questiona aos demais se estão corretas).

(Professora M. AULA 03. 27/04/2016. I' SEMESTRE). 
Nessa situação, a Professora $M$ acionava esquemas similares aos esquemas que também foram evidenciados por Goigoux (200 I), ao analisar padrões de uma professora de alfabetização durante o curso de uma sequência de ensino de leitura. Tais ações dizem respeito ao "esquema de regulação da atenção dos alunos", como, por exemplo: trazer um estudante para o quadro; atribuir uma tarefa para o aluno (vir mostrar uma palavra); dialogar publicamente com ele, atribuindo-lhe o papel de interlocutor potencial para todos os outros alunos da turma; tomar a sua proposta como tema de trabalho coletivo, dentre outros aspectos (GOIGOUX, 200I).

Inferimos, então, que o conhecimento da Professora M sobre as diferentes hipóteses de escrita da sua turma parecia fazer com que tivesse consciência do tipo de atendimento requerido por cada aprendiz. Ou seja, a docente sabia quais alunos conseguiriam desenvolver a atividade com a ajuda de um colega mais experiente e quais precisariam de um atendimento mais direcionado por sua mediação. Tal conhecimento também refletia na mobilização de outro esquema: as atividades diferenciadas.

Esses tipos de atividades, quando desenvolvidas (5/I5), buscavam atentar para as potencialidades das crianças. Sendo assim, as atividades diferenciadas propostas se assentavam nas possibilidades de resolução apresentadas pelos alunos, como também na tentativa de levá-los a evoluir em seus conhecimentos sobre o SEA. Isso pôde ser percebido em uma das aulas (Aula 09), quando a docente dividiu a turma em dois grupos e propôs dois tipos de tarefas.

Nesse dia, a professora, que já havia realizado um trabalho de cópia e leitura do poema "Imagens da infância" com todos os alunos, dividiu a turma em dois grupos e para cada um propôs um tipo de tarefa. Para o grupo de alunos com hipótese alfabética de escrita (AI, A2, A3, A4, A9, Al2, AI 5, A22 e A23) a docente solicitou a escrita de poemas, e para o grupo com níveis que variavam desde o pré-silábico até o alfabético (A5, A6, A8, Al0, Al I, Al4, Al6, Al7, Al8, Al9, A20 e A24), a Professora M propôs que fizessem uma atividade do quadro, que solicitava a leitura de algumas palavras (PIPA, PIÃO, BONECA, CASINHA) e o desenho das mesmas, como também a identificação dessas palavras no poema que havia sido trabalhado.

À medida que os alunos do segundo grupo, sentados à frente da sala, finalizavam a tarefa, a professora formava alguns agrupamentos ou os mantinham sozinhos (A5 e Al6; A8 e Al7; AII, AI9 e A20; A I0; A I 8) e entregava o alfabeto móvel para montagem de palavras ditadas por ela, mas que também pertenciam ao poema estudado. É importante ressaltar que enquanto esse grupo realizava a atividade, a docente também se dirigia ao primeiro grupo, sentado no fundo da sala, para orientá-los a como finalizar a escrita de seus poemas. Percebemos, no entanto, uma atenção mais voltada às crianças que apresentavam dificuldades em relação à apropriação do sistema de escrita alfabética, sentadas na frente da sala. 
Diante disso, a proposição das atividades revela a preocupação da professora em possibilitar o avanço de todos os alunos em seus conhecimentos, no caso dos já alfabéticos de ler e produzir textos, no caso dos demais, de compreender e consolidar as propriedades e convenções do sistema de escrita alfabética. A escolha por atender mais diretamente um grupo, em detrimento do outro, acontecia de forma consciente por parte da docente e acabava refletindo também na progressão das aprendizagens dos alunos, conforme mostraremos mais adiante. Sendo assim, como o trabalho mais sistemático era voltado à apropriação do SEA dos alunos com mais dificuldades, era de se esperar que os avanços aparecessem entre esses aprendizes.

Contudo, é válido ressaltar os tateamentos realizados pela docente ao mobilizar o esquema profissional das atividades diferenciadas, uma vez que algumas das tarefas propostas não se mostraram adequadas aos níveis de escrita alfabética de alguns aprendizes. Em uma das aulas (Aula 02), enquanto o coletivo da sala terminava o trabalho de ordenamento dos versos de um poema em grupo, a docente realizou com Al4 (nível silábico), Al6 (pré-silábico), Al7, Al8, Al9 e A20 (de níveis pré-silábico com início de fonetização) uma atividade diferenciada que envolvia o ordenamento das letras para formação de palavras, conforme apresentado na figura a seguir.

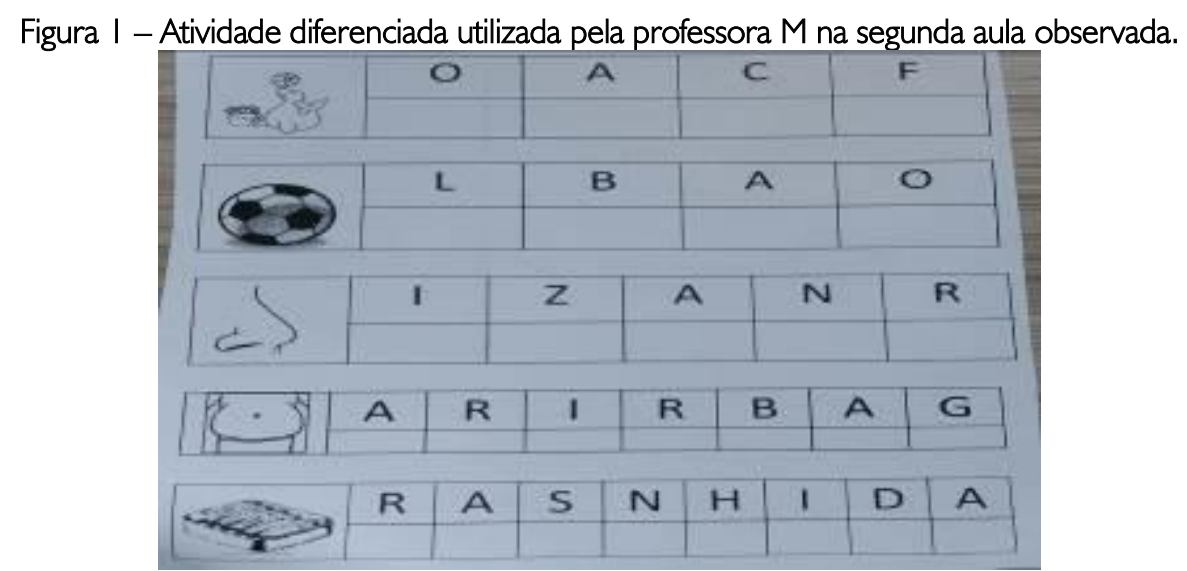

Fonte: Dados da pesquisa (2016).

Como os respectivos alunos se encontravam em níveis iniciais de escrita, a atividade proposta, além das letras, apresentava imagens, com vistas a facilitar a execução da mesma. Contudo, não se tratava de uma atividade adequada para esses aprendizes, tendo em vista que a maioria não compreendia a relação som/grafia. Isso fez com que a professora, diante das dificuldades dos alunos, precisasse os ajudar de maneira sistemática no decorrer de toda a tarefa, questionando-os sobre o nome da figura, repetindo a palavra, segmentando-a por sílabas, com vistas a forçar a comparação da letra com seu som.

Essa busca por realizar um trabalho diferenciado, assim como a inadequação de algumas atividades, já que nem sempre a atividade será "teoricamente" adequada às necessidades de todos os aprendizes, revelam o processo de construção desenvolvido pela Professora M para dar conta da heterogeneidade do 
seu grupo, assim como os tateamentos que vinha fazendo com vistas a encontrar uma prática que atendesse aos diferentes conhecimentos dos seus alunos e os fizessem progredir em suas aprendizagens. Afinal, "[...] uma transformação bem-sucedida paga o preço de numerosas tentativas, abortadas, fracassadas ou abandonadas" (CHARTIER, 2000, p. 164).

Isso também acontecia com o caderno de reforço que foi elaborado pela professora para Al3 (pré-silábico com início de fonetização), Al4 (silábico) e A24 (silábico-alfabético), que apresentavam dificuldades de aprendizagem em relação à leitura e à escrita. Tal caderno começou a ser utilizado a partir do segundo semestre, por isso, não visualizamos a ocorrência desse esquema em outras aulas, sendo utilizado em uma das aulas observadas (I/I5). $\bigcirc$ mesmo foi usado nos momentos de atendimento individual dirigidos aos aprendizes, tendo em vista as dificuldades dos alunos em relação à apropriação do SEA, que ainda persistiam naquele momento do ano letivo.

Esse esquema também se aproxima dos resultados da pesquisa de Goigoux (20 I 6) que diz respeito às atividades pedagógicas complementares utilizadas pelas professoras como forma de diferenciação pedagógica. Contudo, as atividades complementares do caderno de reforço, diferentemente das tarefas propostas pelas professoras investigadas por Goigoux (2016), eram desenvolvidas no próprio horário da aula, em situações de "tempo livre". Ou seja, quando um desses alunos terminava a atividade diferenciada antes do tempo previsto e a classe ainda fazia a tarefa proposta para o coletivo da sala, a professora utilizava o caderno de reforço, fazendo assim, um bom aproveitamento do tempo pedagógico.

Ao focarmos nossa análise no contexto da sala de aula, inferimos que a mobilização desses esquemas, dos gestos e posturas contribuiu para a evolução das aprendizagens de escrita da maioria da turma. No Quadro 2, podemos observar as progressões de escrita dos alunos ao final do ano letivo.

Quadro 2 - Perfil inicial e final de escrita dos alunos da turma de $2^{\circ}$ ano da professora $M$.

\begin{tabular}{|c|c|c|c|c|c|c|}
\hline Níveis de apropriação do SEA & $\begin{array}{c}\text { Identificação dos Alunos } \\
\text { - Perfil inicial - }\end{array}$ & $\begin{array}{l}\text { Identificação dos Alunos } \\
\text { - Perfil Final - }\end{array}$ & \multicolumn{2}{|c|}{$\begin{array}{l}\text { Qtd. } \\
\text { Inicial }\end{array}$} & \multicolumn{2}{|c|}{$\begin{array}{l}\text { Qtd. } \\
\text { Final }\end{array}$} \\
\hline Pré - Silábico (PI) & AIO, AI9 & - & 2 & $8,3 \%$ & 0 & $0 \%$ \\
\hline $\begin{array}{l}\text { Pré - Silábico com início de } \\
\text { fonetização (PII) }\end{array}$ & $\begin{array}{c}\mathrm{A} 5, \mathrm{~A}|3, \mathrm{~A}| 6, \mathrm{Al} 7 \\
\mathrm{~A} \mid 8, \mathrm{~A} 20 \\
\end{array}$ & - & 6 & $25 \%$ & 0 & $0 \%$ \\
\hline Silábico (S) & $\mathrm{A} 8, \mathrm{~A} \mid 4$ & - & 2 & $8,3 \%$ & 0 & $0 \%$ \\
\hline Silábico - Alfabético (SA) & $\mathrm{A} 7, \mathrm{~A} 1 \mathrm{I}, \mathrm{A} 24$ & $\mathrm{~A} 14, \mathrm{~A} 24$ & 3 & $12,5 \%$ & 2 & $8,3 \%$ \\
\hline Alfabético inicial (Al) & - & AlO & 0 & $0 \%$ & I & $4,1 \%$ \\
\hline Alfabético intermediário (All) & $\mathrm{A} 3, \mathrm{~A} 4, \mathrm{~A} 6, \mathrm{~A} 9, \mathrm{~A} 2 \mathrm{I}$ & $\begin{array}{c}\mathrm{A} 5, \mathrm{~A} 8, \mathrm{AlI}, \mathrm{Al} 3, \mathrm{Al} 6 \\
\mathrm{~A} 17, \mathrm{~A} \mid \mathrm{8}, \mathrm{A} 19, \mathrm{~A} 20\end{array}$ & 5 & $20,8 \%$ & 9 & $37,5 \%$ \\
\hline Alfabético consolidado (AllI) & $\begin{array}{c}A 1, A 2, A I 2, A I 5, A 22 \\
A 23\end{array}$ & $\begin{array}{c}\mathrm{Al}, \mathrm{A} 2, \mathrm{~A} 3, \mathrm{~A} 4, \mathrm{~A} 6, \mathrm{~A} 7 \\
\mathrm{~A} 9, \mathrm{Al} 2, \mathrm{Al} 5, \mathrm{~A} 2 \mathrm{l} \\
\mathrm{A} 22, \mathrm{~A} 23\end{array}$ & 6 & $25 \%$ & 12 & $50 \%$ \\
\hline $\begin{array}{l}\text { Alfabético com escrita } \\
\text { convencional (AIV) }\end{array}$ & - & 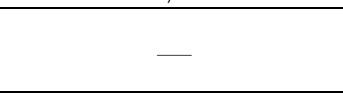 & 0 & $0 \%$ & 0 & $0 \%$ \\
\hline Total & - & - & 24 & $\approx 100 \%$ & 24 & $\begin{array}{c}\approx 100 \\
\%\end{array}$ \\
\hline
\end{tabular}

Fonte: Dados da pesquisa (2016). 
A partir desse quadro, podemos identificar o quanto e como os alunos avançaram em seus conhecimentos sobre o sistema de escrita alfabética. Ao final do ano letivo, a maioria $(91,5 \%)$ dos aprendizes já apresentava uma hipótese alfabética de escrita, estando 8,3\% no nível silábico-alfabético. Todos os aprendizes que, inicialmente, se encontravam em níveis iniciais de escrita (pré-silábico e présilábico com início de fonetização), avançaram para o nível alfabético inicial ou intermediário; os de nível silábico para o silábico-alfabético ou alfabético intermediário, e os silábico-alfabético para o alfabético intermediário ou consolidado. Além disso, destacamos, ainda, as evoluções das crianças que já iniciaram o ano com uma hipótese alfabética intermediária de escrita, que também conseguiram evoluir para uma hipótese consolidada.

Por outro lado, também visualizamos a permanência de alguns aprendizes nas hipóteses silábicoalfabética (A24) e alfabética consolidada ( $\mathrm{AI}, \mathrm{A} 2, \mathrm{AI} 2, \mathrm{AI}$ 5, A22, A23). Deste último grupo, nenhum aluno conseguiu avançar para uma escrita convencional, tendo em vista a dificuldade em relação ao uso adequado de algumas regras ortográficas. Essa maior concentração de alunos no nível alfabético consolidado e a ausência de progressão desses aprendizes para uma escrita convencional pode ser entendida como um reflexo da maior atenção proferida aos alunos que apresentavam mais dificuldades com a escrita. Essa atenção foi importante, pois possibilitou que nenhum aluno terminasse o ano letivo sem compreender o que a escrita representa/nota (MORAIS, 20I2).

Sendo assim, o perfil final ora apresentado sinaliza avanços, tendo em vista que tanto os alunos que apresentavam dificuldades em compreender as propriedades e convenções do sistema de escrita alfabética, quanto os que já compreendiam esse funcionamento no início do ano, conseguiram majoritariamente evoluir em seus conhecimentos.

\section{CONCLUSÃO}

Ao analisarmos as maneiras de fazer mobilizadas pela professora $M$ no cotidiano da sala de aula, percebemos que a heterogeneidade não era um fenômeno indiferente às suas ações, sendo evidenciados alguns "esquemas profissionais, posturas e gestos profissionais" nesse atendimento. Estes revelaram uma atenção aos diferentes conhecimentos dos alunos, em especial àqueles aprendizes que apresentavam dificuldades com a leitura e a escrita. Por outro lado, os alunos que não apresentavam tantas dificuldades também eram levados em consideração.

Sendo assim, identificamos o atendimento individualizado, as ajudas e intervenções diretas, os agrupamentos, a interação professora-aluno nas situações coletivas de ensino, as atividades diferenciadas e o caderno de reforço como esquemas mobilizados pela docente para dar conta da heterogeneidade do seu grupo-classe. Atrelado a isso, observamos ainda o gesto profissional de apoio e a postura de 
acompanhamento que a professora desenvolvia junto a determinados aprendizes, assim como, gestos que buscavam manter a boa atmosfera da classe.

Ao mobilizar alguns desses esquemas, a exemplo das atividades diferenciadas e o caderno de reforço, percebemos os tateamentos e esforços da professora em propor atividades que estivessem de acordo com as possibilidades de resolução dos aprendizes. Além disso, era evidente o movimento por parte da docente de se colocar à disposição para ajuda e atendimento individualizado nas situações de atividade coletiva.

Com isso, a Professora M evidenciava seu conhecimento acerca da heterogeneidade que permeava a classe e buscava agir considerando esse aspecto, com o intuito de possibilitar o avanço das aprendizagens de cada criança. Nessa direção, a docente parecia dispor de um conhecimento individualizado acerca de seus alunos para que a progressão acontecesse com base nas competências e habilidades de cada um, ou seja, partindo daquilo que os aprendizes já sabiam para aquilo que ainda precisavam aprender, em vez de idealizar uma aprendizagem padrão para a turma em geral.

Essa evolução das aprendizagens pôde ser observada no perfil de saída das crianças, por meio das diagnoses de escrita que foram realizadas ao final do ano letivo. Nessas atividades, a maioria dos alunos apresentou avanços significativos em seus conhecimentos, com saltos qualitativos de aprendizagem. No que se refere aos níveis de apropriação do sistema de escrita alfabética, verificamos uma progressão das hipóteses, passando dos níveis iniciais de escrita para o nível silábico-alfabético e alfabético. Além disso, destacamos a ausência de registros com escritas convencionais, o que revela a preocupação mais restrita da professora em fazer com que os alunos das hipóteses iniciais atingissem o nível alfabético. Contudo, não podemos considerar a permanência ao longo do ano no mesmo nível de escrita enquanto ausência total de progressão, haja vista que certas propriedades e convenções do SEA podem ter sido apreendidas.

Diante do exposto, os resultados revelam a inexistência de uma relação direta entre o uso de métodos tradicionais e a consequente alfabetização dos alunos, uma vez que a Professora $M$ conseguiu fazer os alunos avançarem significativamente sem se utilizar de um método tradicional para isso. Sendo assim, consideramos que não é a volta de um método silábico/fônico ou global, de perspectiva homogeneizadora, que propiciará a aprendizagem da língua escrita, mas sim, a valorização da heterogeneidade de saberes sobre a leitura e a escrita que permeiam os alunos da classe. Em outras palavras, desenvolver diferentes caminhos no atendimento à diversidade de conhecimentos que os aprendizes apresentam.

\section{REFERÊNCIAS}

ANDRÉ, M. Etnografia da prática escolar. Campinas, SP: Papirus, 1995. 
BARDIN, L. Análise de conteúdo. 3. ed. Lisboa: Edições 70, 2004.

BARRETTO, E. S. S.; SOUSA, S. Z. Estudos sobre ciclos e progressão escolar no Brasil: uma revisão. Educação e Pesquisa, São Paulo, v. 30, n. I, p. II-30, jan./abr. 2004.

BATISTA, A. A. G.; GALVÃO, A. M. O.; KLINK, K. Livros escolares de leitura: uma morfologia ( 866 1956). Revista Brasileira de Educação, Rio de Janeiro, n. 20, Maio/Jun/Jul/Ago. 2002.

BUCHETON, D. Les postures d'écriture et de lecture: la diversité des modes de penser-parlerapprendre. Lausanne: Langage § Pratiques, n. 37, p. 29-39, 2006.

BUCHETON, D.; SOULÉ, Y. Les gestes professionnels et le jeu des postures de l'enseignant dans la classe: un multi-agenda de préoccupations enchâssées. Éducation et didactique, v. 3, n. 3, p. 29-48, 2009.

CHARTIER, A. M. Fazeres ordinários da classe: uma aposta para a pesquisa e para a formação. Educação e Pesquisa, São Paulo, v. 26, n. 2, p. 157-168, jul./dez. 2000.

CHARTIER, A. M. Práticas de leitura e escrita: história e atualidade. Belo Horizonte: Ceale/Autêntica, 2007. p. 185-207.

CHARTIER, A. M. L'école et la lecture obligatoire: Histoire et paradoxes des pratiques d'enseignement de la lecture. Paris: Retz, 20 15. p. 5I-73.

COLOMINA, R.; ONRUBIA, J. Interação educacional e aprendizagem escolar: a interação entre alunos. In: C. COLL, et al (Orgs.) Desenvolvimento psicológico e educação. 2. ed. Porto Alegre: Artmed, 2004.

CRUZ, M. C. S. Tecendo a alfabetização no chão da escola seriada e ciclada: a fabricação das práticas de alfabetização e a aprendizagem da escrita e da leitura pelas crianças. 20 I2. 34 I f. Tese (Doutorado em Educação) - Centro de Educação, Universidade Federal de Pernambuco, Recife, 2012.

DOURADO, V. C. A. Ensino ajustado à heterogeneidade de aprendizagens no "ciclo" de Alfabetização: práticas de professoras experientes do $2^{\circ}$ Ano. 2017. 280 f. Tese (Doutorado em Educação) - Centro de Educação, Universidade Federal de Pernambuco, Recife, 2017.

DURAN, M. C. G. Maneiras de pensar o cotidiano com Michel de Certeau. Diálogo Educ., Curitiba, v. 7, n. 22, p. II5-128, set./dez. 2007.

FERREIRO, E. Reflexões sobre alfabetização. 24. ed. São Paulo: Cortez, 2001 .

FERREIRO, E.; TEBEROSKY, A. Psicogênese da língua escrita. Porto Alegre: Artmed, 1999. p. | 9 |-245.

FILHO, L. M. F.; VIDAL, D. G. Os tempos e os espaços escolares no processo de institucionalização da escola primária no Brasil. Revista Brasileira de Educação, Rio de Janeiro, n. I4, Mai/Jun/Jul/Ago. 2000.

GOIGOUX, R. Lector in didactica: Un cadre théorique pour l'étude de l'activité du maître de lecture. In: J. P. BERNIÉ (Org.). Apprentissage, Développement et significations, Presses Universitaires de France, 200।. p. 129-I 53.

GOIGOUX, R. Rien de plus pratique qu'une bonne théorie ? Si, deux! Les concepts de schème et de genre au service d'une analyse didactique de l'activité d'enseignement. In: MERRI, M. (Ed.). Activité humaine et conceptualisation. Questions à Gérard Vergnaud. Toulouse: PUM, 2007. p. 91-102. 
GOIGOUX, R. Synthèse du rapport de recherche : étudo de l'influence des pratiques d'enseignement de la lecture et de l'écriture sur la qualité des prémiers apprentissages. 2016. Disponínel em: http://ife.ens-lyon.fr/ife/recherche/lire-ecrire/rapport/rapport.

Acesso em: 15/09/2017 I 5 set. 2017.

GOIGOUX, R.; VERGNAUD, G. Schèmes professionnels. Revue de l'association internationale de recherches en didactique du français, AiRDF, v. 36, p. 7- 10, 2005.

MAURICE, J. J. Des contraintes du métier d'enseignant participent-elles à la construction de son expérience? In: P. DESSUS; E. GENTAZ. (eds.). Apprentissages et enseignement: sciences cognitives et education. Paris, Dunod, 2006. p. 219-240.

MORAIS, A. G. Sistema de escrita alfabética. São Paulo: Editora Melhoramentos, 2012.

NASCIMENTO, M. C. B. Análise da prática cotidiana de uma professora do terceiro ano que tem alunos com hipóteses diferentes sobre o SEA: suas fabricações e seus saberes. 2017. 125 f. Dissertação (Mestrado em Educação) - Centro de Educação, Universidade Federal de Pernambuco, Recife, 2017.

OLIVEIRA, S. A. O ensino e a avaliação do aprendizado do sistema de notação alfabética numa escolarização organizada em ciclos. 2004. 29 I f. Dissertação (Mestrado em Educação) - Centro de Educação, Universidade Federal de Pernambuco, Recife, 2004.

OLIVEIRA, S. A. Progressão das atividades de língua portuguesa e o tratamento dado à heterogeneidade das aprendizagens: um estudo da prática docente no contexto dos ciclos. 2010.446 f. Tese (Doutorado em Educação) - Centro de Educação, Universidade Federal de Pernambuco, Recife, 2010.

SÁ, C. F. Alfabetização em turmas multisseriadas: estratégias docentes no tratamento da heterogeneidade de aprendizagens. 20I5. Dissertação (Mestrado em Educação) - Centro de Educação, Universidade Federal de Pernambuco, Recife, 2015.

SILVA, N. N. T. O tratamento da heterogeneidade de conhecimentos dos alunos sobre a leitura e a escrita: saberes e práticas de professoras alfabetizadoras. 20I4. I36 f. Dissertação (Mestrado em Educação Contemporânea) - Centro Acadêmico do Agreste, Universidade Federal de Pernambuco, Caruaru, 2014.

SILVA, K. V. N. G. Heterogeneidade de conhecimentos sobre o sistema de escrita alfabética: estudo da prática docente. 2016. 200 f. Dissertação (Mestrado em Educação) - Centro de Educação, Universidade Federal de Pernambuco, Recife, 2016.

SILVEIRA, R. C. A heterogeneidade no último ano do ciclo de alfabetização e as estratégias docentes para o ensino de produção de textos. 2013.208 f. Dissertação (Mestrado em Educação) - Centro de Educação, Universidade Federal de Pernambuco, Recife, 2013.

TARDIF, M. Saberes docentes e formação profissional. 9. ed. Petrópolis, RJ: Vozes, 2008. p. 31-53. 


\section{COMO CITAR ESSE ARTIGO}

\section{Associação Brasileira de Normas Técnicas (ABNT)}

TORRES DA SILVA, Nayanne Nayara; ALBUQUERQUE, Eliana Borges Correia de. A heterogeneidade de conhecimentos sobre o sistema de escrita alfabética: práticas de ensino e aprendizagens dos alunos. Debates em Educação, Maceió, n. 12, p. 79-99, set. 2020. ISSN 2175-6600. Disponível em: https://www.seer.ufal.br/index.php/debateseducacao/article/view/997I. Acesso em: dd mmm. aaaa.

\section{American Psychological Association (APA)}

Torres da Silva, N., \& Albuquerque, E. (2020). A heterogeneidade de conhecimentos sobre o sistema de escrita alfabética: práticas de ensino e aprendizagens dos alunos. Debates em Educação, 12 (Esp), 79-99. doi: https://doi.org/l0.28998/2175-6600.2020v12nEspp79-99 